\author{
<기술논문> \\ 적층 접시스프링의 정적 거동 특성 \\ 김 영 흡 $^{(1)} \cdot$ 조 승 현 ${ }^{1)} \cdot$ 박 동 훈 ${ }^{2)}$ \\ 동양미래대학교 기계과 ${ }^{1)} \cdot$ 시스톤 테크놀로지스(주 $)^{2)}$
}

\title{
Static Behavior Characteristics of Disc Spring Stacks
}

\author{
Youngheub $\mathrm{Kim}^{* 1)} \cdot$ Seunghyun $\mathrm{Cho}^{1)}$ - Dong Hoon Park ${ }^{2)}$ \\ ${ }^{1)}$ Department of Mechanical Engineering, Dongyang Mirae University, Seoul 152-714, Korea \\ ${ }^{2)}$ C-stone Technologies, \#410 R\&DB Center, 906-5 Iui-dong, Yeongtong-gu, Suwon-si, Gyeonggi 443-766, Korea
}

(Received 7 May 2012 / Revised 4 February 2013 / Accepted 20 February 2013)

\begin{abstract}
The wide application of disc springs to the designing of mechanical products with space limit is mainly attributable to their property of sustaining large axial load with small displacement. Due to the impediments in expecting the final results caused by the significant differences existing between a single unit and a stacked form, the force-displacement characteristics of a single disc spring and stacked disc springs are mainly examined in this study. In particular, the hysteresis of the series stack and the parallel stack will be investigated through the FE analysis and the analytical results will finally be compared with the acquired experimental data. In the final result, the analytical results were in accordance with the experimental data.
\end{abstract}

Key words : Disc spring(접시스프링), Behavior characteristics(거동 특성), Series stack(직렬 적층), Parallel stack (병렬 적층), Friction(마찰), 이력(Hysteresis)

\section{1. 서 론}

접시 스프링은 원뿔 형태의 원형 판스프링으로서 판의 두께가 일정하며 작용 하중이 내경 상부와 외 경 하부의 가장자리에 고르게 분산되는 특징이 있 다. 접시스프링은 작은 변위로 큰 축방향의 하중을 지지하는데 이상적으로 사용될 수 있는 기계요소로 서, 자동차를 비롯하여 선박 해양 탐사시설, 건설장 비, 보일러, 소각로, 기계 공구, 교통시설 등 거의 모 든 산업 분야에 광범위하게 적용되고 있다.

접시스프링은 1867년 Julien-Francoise Belleville 가 현재 사용되는 접시스프링 형태에 대한 특허를 취득 ${ }^{1)}$ 한 이후 다양한 제품에 꾸준하게 적용되어 왔 고, 그 특성에 대한 연구 또한 다양하게 이루어져 왔 다. 외국의 경우 접시스프링의 하중-변위 곡선을 계

*Corresponding author, E-mail: prokyh@dongyang.ac.kr
산하는 방정식이 처음 제시된 이후 ${ }^{2}$ 전문 스프링 업 체를 중심으로 이론과 설계 실무에 대한 내용이 제 시 $^{3)}$ 되었으며, 접시스프링이 많이 적용되는 승용차 의 자동변속기 대하여 그 특성을 고려한 설계 연구 ${ }^{4}$ 가 이루어진 바 있다. 국내의 경우 접시스프링의 적 층 방법에 따른 진동/충격 절연효과를 분석한 연구 ${ }^{5}$ 를 비롯하여 접시스프링의 형상 및 적층 개수에 따 른 충격 시의 비선형 특성을 고찰한 연구 ${ }^{6}$ 및 단일 접시스프링의 마찰을 고려한 하중, 변위 곡선에 대 한 연구 ${ }^{7}$ 등이 이루어진 바 있다. 또한, 접시스프링 과 고무링으로 구성된 완충장치에 대한 연구, ${ }^{8)}$ 자동 변속기에 적용된 접시스프링의 최적설계에 대한 연 구, ${ }^{9)}$ 접시스프링의 해석 방법을 이용하여 승용차용 클러치에 사용되는 스프링의 강성 해석에 대한 연 구 $^{10)}$ 등 접시스프링이 적용된 시스템에 대한 연구가 이루어졌다. 이러한 연구는 단일 접시스프링을 대 
상으로 하중-변위에 대한 선형 또는 비선형 해석을 수행하였거나 접시스프링이 적층된 경우에 대해서 도 수치해석을 통하여 기존 수식과의 일치 여부를 검증하거나 진동 측면에서 고찰한 것이다.

본 연구에서는 직렬 및 병렬 형태로 적층된 접시 스프링의 개수 및 마찰계수의 변화에 의한 힘-변위 특성에 대한 영향을 평가하기 위하여 해석과 실험 을 수행하고 그 하중을 받는 경우의 거동 특성을 고 찰하였다.

\section{2. 수치해석}

\section{1 접시스프링의 마찰 특성}

단일 접시스프링의 압축과 복원 시에 작용하는 마찰력은 Fig. 1에 나타난 바와 같다. 즉, 접시스프링 이 압축될 때 접시스프링 모서리에서 발생한 마찰 력은 회전중심에 모멘트를 발생시키고, 이것은 압 축 하중이 회전중심에 대하여 발생시키는 모멘트와 반대 방향으로 작용하여 압축에 요구되는 하중이 증가하게 된다. 이와는 반대로 복원 시에는 마찰력 에 의한 모멘트가 압축 하중에 의한 모멘트와 같은 방향으로 작용하여 발생한 마찰력만큼 압축 하중이 감소하게 된다. 이러한 마찰력은 하중을 받는 표면 거칠기, 스프링 모서리의 라운드 크기, 윤활제의 유 무 등에 따라 달라진다.

접시 스프링은 그 적층 방법에 따라서 압축과 인 장 시 각각의 접시스프링 사이, 접시스프링과 가이 드 및 하중이 작용하는 모서리 등에서 마찰력이 발 생하게 되고, 이 마찰력으로 인하여 접시스프링은 적층되는 방법과 스프링의 개수에 따라 다양한 이 력현상(hysteresis)을 나타낸다.

Fig. 2에 나타난 바와 같이 접시스프링을 병렬로

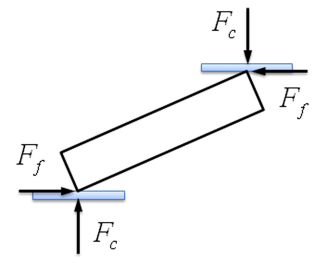

(a) Compression

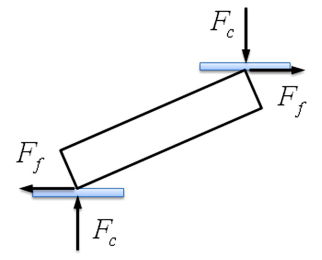

(b) Release
Fig. 1 Friction forces of single disc spring under compression and release

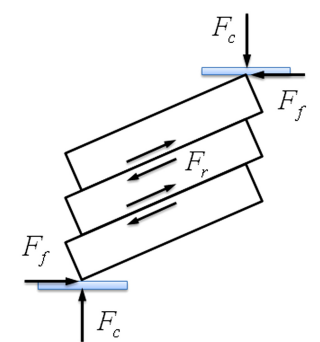

(a) Compression

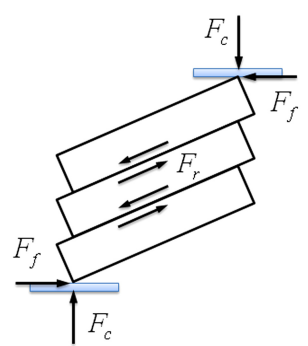

(b) Release
Fig. 2 Friction forces of stacks of disc springs under compression and release

적층하는 경우 적층한 각각의 접시스프링의 접촉되 는 면에서 마찰력이 발생하게 된다. 이 마찰력은 적 층된 스프링의 개수에 비례하는데, 압축 시 압축하 중의 증가와 복원 시 압축하중의 감소를 발생시킨 다. 이러한 접시스프링의 적층 시 이력현상은 적층 된 스프링의 개수가 많을수록 커지는데 이는 적층 된 접시스프링에서 각각의 기하학적 형상 변화의 누적에 의한 것이다.

접시스프링을 직렬로 적층할 때에는 병렬로 적층 하는 경우에 비해 매우 작은 마찰력이 발생하는데, 접시스프링 내경의 곡선을 스프링 및 가이드 사이 의 마찰력이 최소화되도록 설계하기 때문이다.

\section{2 해석 모델}

본 연구에서는 직렬 및 병렬 형태로 적층된 접시 스프링의 거동특성을 고찰하기 위해 비선형거동해 석에 널리 사용되고 있는 $\mathrm{MSC} / \mathrm{MARC}$ 프로그램을 사용하여 유한요소 해석을 위한 2 차원 축대칭 접촉 모델을 구성하였다. 접시스프링의 재질은 Soft $50 \mathrm{Cr}$ $\mathrm{V}-4$ 이고 탄성계수는 $106 \mathrm{GPa}$ 이며, 포아송비는 0.29 이다. Fig. 3은 해석에 사용된 단일 접시스프링 모델 의 사양을 나타내고 있다.

Fig. 4(a), (b)는 각각 10개의 접시스프링이 직렬과 병렬 형태로 적층된 모델로서 접시스프링은 변형 가능한 메쉬로 모델링하였고, 지지부는 강체로 모 델링한 결과를 나타내고 있다.

해석 시 접시스프링은 강체에 의해 축방향으로 압축하는 조건을 부여하였고, 접시스프링과 강체사 이의 접촉면에 마찰계수가 균일하다고 가정하였다.

접촉면의 마찰계수는 0.005 와 0.01 로 변화시켰고, 


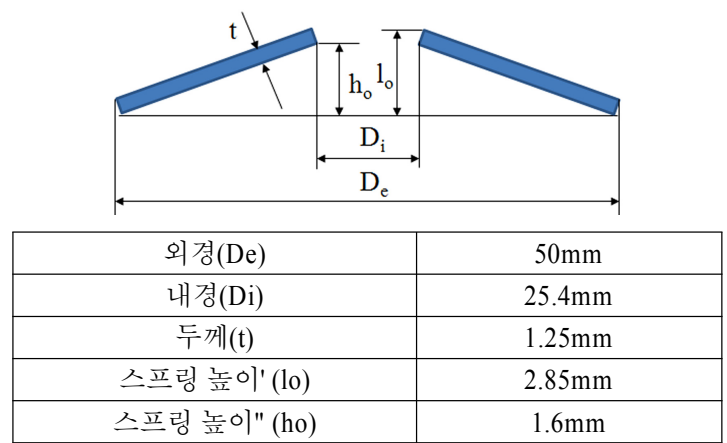

Fig. 3 Specification of the disk spring model

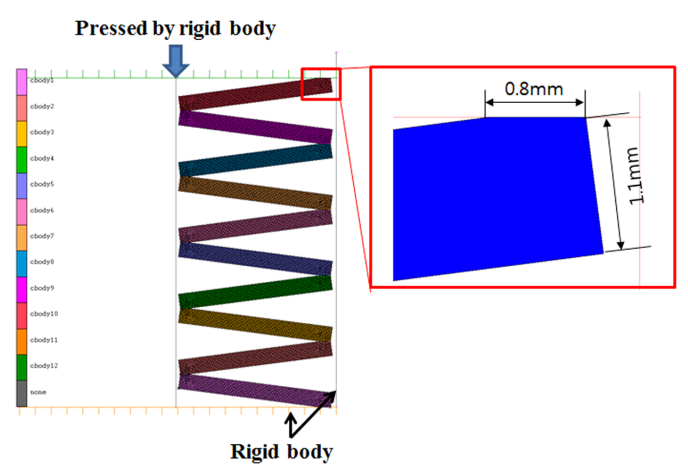

(a) Series stack

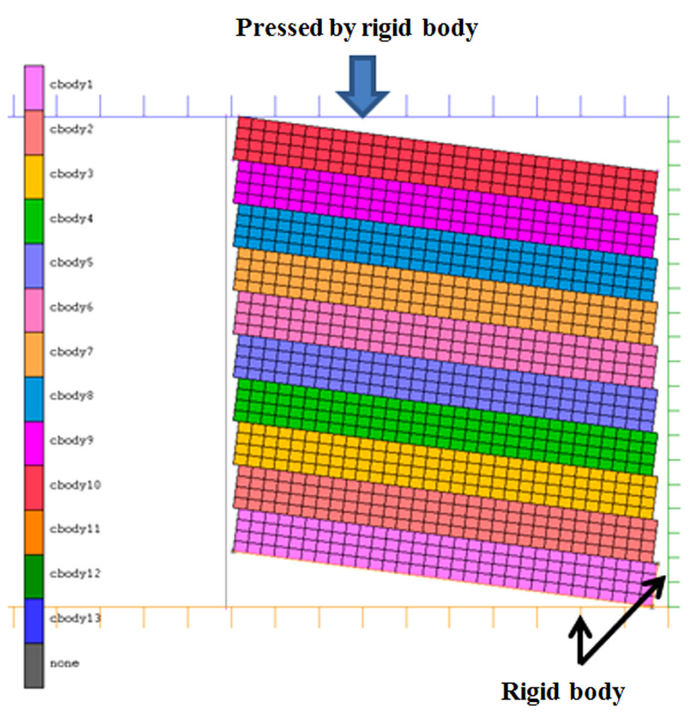

(b) Parallel stack

Fig. 4 Finite element models for stack of disc springs

스프링 개수는 $1,2,4,6,8,10$ 개로 변화시켰으며 스 프링의 traveling 거리에 대한 스프링력을 분석하기

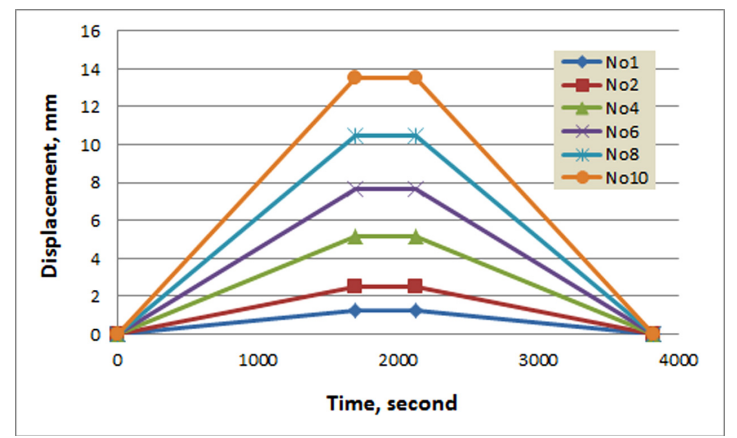

Fig. 5 Compression distance condition for series stack

위해 변화시킨 스프링의 압축 길이는 병렬은 $1.2 \mathrm{~mm}$ 로 일정하게 하였으며, 직렬방식은 Fig. 5 와 같이 다 르게 하였다.

\section{3 해석결과}

Fig. 6(a), (b)는 접시스프링의 변위와 힘을 측정하 기위한 위치를 나타내고 있는데, 스프링 모델에서 거동의 최대 변위를 나타내는 부분을 선택하였다.

Fig. 7은 직렬과 병렬 적층 상태에서 접시스프링 의 마찰계수가 0.005 일 때 스프링의 개수에 따라 발 생한 변위와 힘을 나타낸 결과이다.

Fig. 7(a)는 직렬 적층 접시스프링의 해석 결과로 서 스프링 개수가 증가할수록 동일한 힘에 대하여 압축된 스프링 변위의 누적에 의하여 총 변위가 증 가하였음을 알 수 있다.

Fig. 7(b)는 병렬 적층 접시스프링의 해석 결과인 데, 해석 시 스프링의 압축 변위를 $1.2 \mathrm{~mm}$ 로 일정하 게 입력을 주었으므로 스프링 개수와 관계없이 변 위는 약 $1.2 \mathrm{~mm}$ 로 발생하였으나, 힘은 스프링 개수 가 증가할수록 증가하여, 스프링 개수가 1 개에서 10 개로 증가할 때 힘은 약 9.6 배 증가하였다.

Fig. 7에 나타난 결과에 의하면 직렬 적층 접시스 프링은 압축 후 복귀하는 과정에서 이력현상이 크 지 않지만, 병렬 적층 접시스프링은 압축 후 복귀하 는 과정에서 힘이 감소하는 이력현상이 뚜렷하게 나타났음을 알 수 있다. 또한, 스프링의 개수가 증가 할수록 스프링 힘의 감소폭은 증가하고 이력현상이 심화되었는데, 이것은 병렬형태 스프링의 압축-복 귀 과정에서 표면에서 발생하는 마찰력의 영향을 더 크게 받기 때문으로 평가된다. 


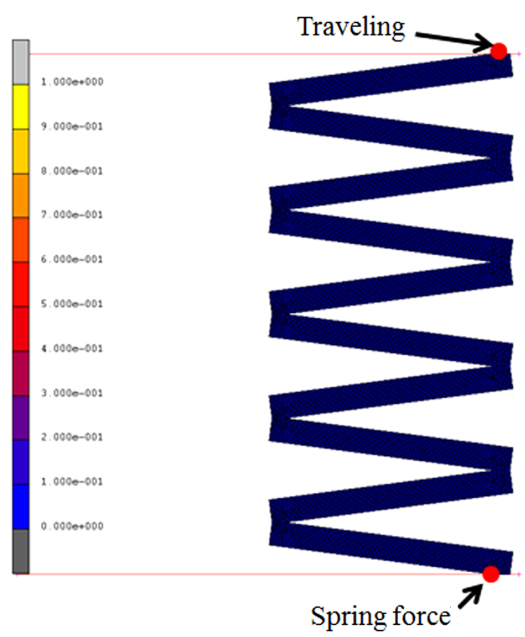

(a) Series stack

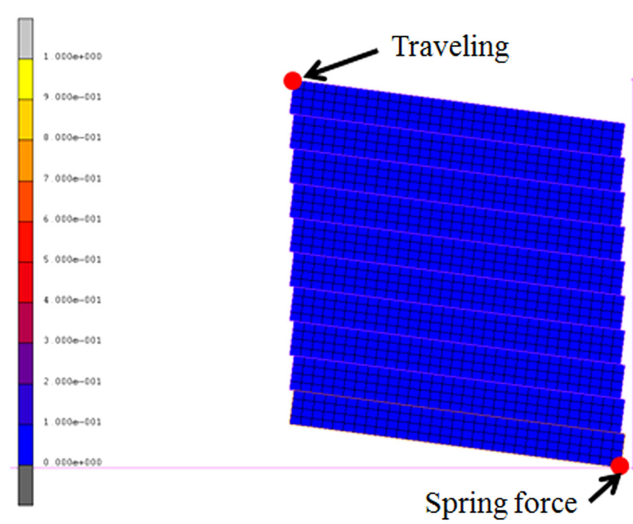

(b) Parallel stack

Fig. 6 Results obtaining positions

Fig. 8은 직렬과 병렬 적층 상태에서 접시스프링 의 마찰계수가 0.01 일 때 스프링의 개수에 따라 발 생한 변위와 힘을 나타낸 결과이다.

Fig. 8(a)의 직렬 적층에 대한 해석 결과는 Fig. 7(a) 의 마찰계수가 0.005 일 때와 비교할 때 큰 차이가 없 는 것을 알 수 있는데, 이것은 직렬 적층의 경우 접 촉 면적이 매우 작아 마찰계수의 영향을 크게 받지 않았음을 알 수 있다.

Fig. 8(b)의 병렬 적층의 경우 마찰계수가 0.01 로 증가하면 Fig. 7(b)와 동일 조건에서 변위가 $1.1 \mathrm{~mm}$ 로 마찰계수 0.005 인 Fig. 7(a)에 비해 감소하였고, 최대 힘은 유사하지만 압축 후 복귀할 때 힘의 감소 폭이 증가하여 이력현상이 심해진 것을 알 수 있다.

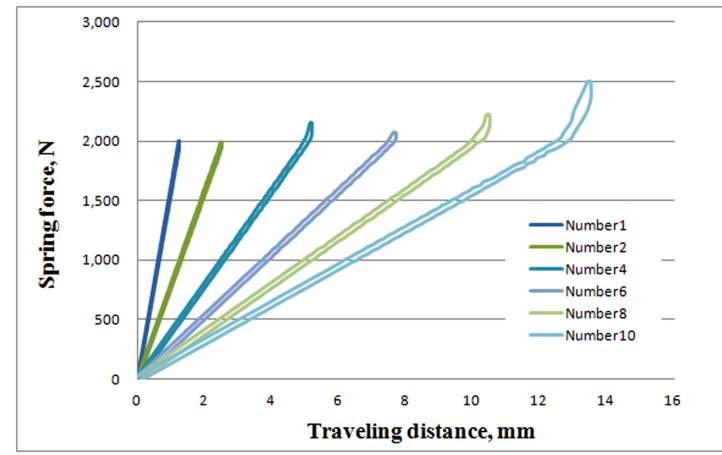

(a) Series stack

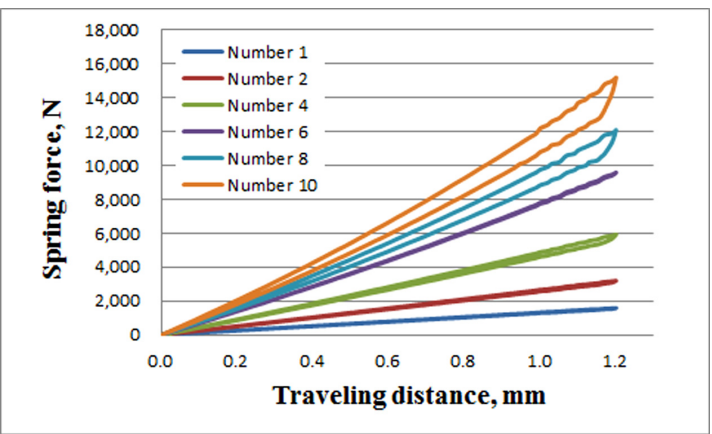

(b) Parallel stack

Fig. 7 Spring force of disk springs by numerical analysis as a function of traveling distance with friction coefficient 0.005

이것은 병렬형태 스프링의 경우 접촉 표면적이 크 기 때문에 마찰계수의 영향을 크게 받기 때문이다.

Fig. 9는 마찰계수가 0.01 이고, 최대 압축이 발생 하였을 때 직렬형태 접시스프링에서 발생한 von Mises 응력 분포를 나타낸 결과이다.

스프링 개수가 1 개일 때 $1,085 \mathrm{MPa}$ 의 응력이 접시 스프링의 내경에서 발생하였고 스프링의 개수가 10 개로 증가하면서 이 응력이 $1,315 \mathrm{MPa}$ 로 증가하였 다. 동일한 조건의 병렬형태의 접시스프링에서 발생 한 von Mises 응력은 스프링이 10 개인 경우 $1,132 \mathrm{MPa}$ 의 내경에서 응력이 발생하였다.

이 해석 결과로부터 직렬 적층 접시스프링에서 국부적인 접촉면적에 의해 높은 응력이 발생하고 스프링의 개수가 증가할수록 힘의 증가에 의해 높 은 응력이 발생하며, 특히 스프링의 내경 쪽에서 높 은 응력이 발생하는 것을 알 수 있다. 


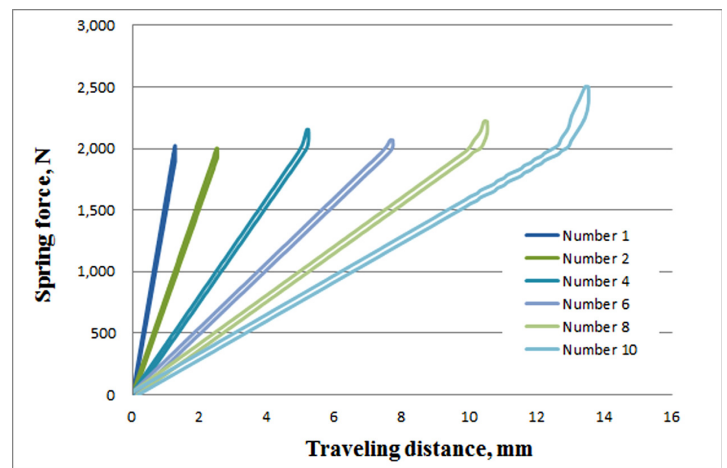

(a) Series stack

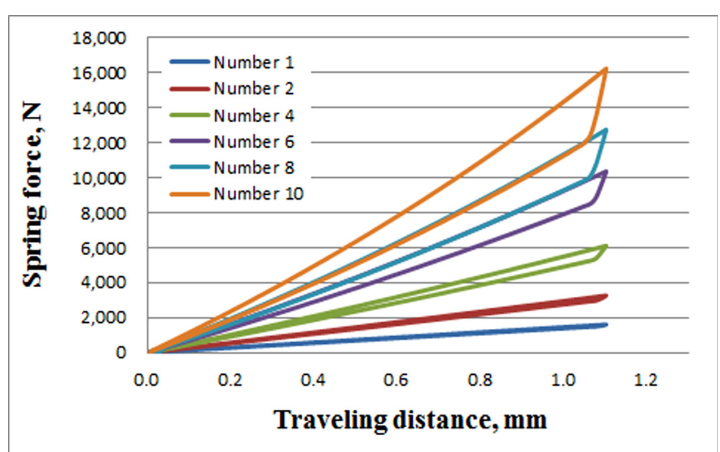

(b) Parallel stack

Fig. 8 Spring force of disk springs by numerical analysis as a function of traveling distance with friction coefficient 0.01

\section{3. 접시스프링 거동 실험}

\section{1 실험 장치}

Photo. 1은 실험에 사용된 접시스프링을 직렬과 병렬로 적층한 모습을 나타내고 있는데, 단일 접시 스프링은 Fig. 3의 모델에 나타난 바와 같이 외경 $50 \mathrm{~mm}$, 내경 $25.4 \mathrm{~mm}$, 두께 $1.25 \mathrm{~mm}$, 자유높이 2.85 $\mathrm{mm}$ 를 가진다.

Photo. 2는 적층된 접시스프링에 하중을 가하기 위한 실험장치를 나타내고 있다. 이 장치는 $2.2 \mathrm{~kW}$ 의 모터에 의해 회전하며 기어비에 의하여 최대 토 크 $1,800 \mathrm{Nm}$, 캠에 의한 최대 변위 $30 \mathrm{~mm}$ 를 시험 시 편에 가할 수 있다.

Photo. 3은 적층된 접시스프링에 하중을 가하기 위한 지그와 이를 실험 장치에 장착한 모습을 나타 내고 있다.

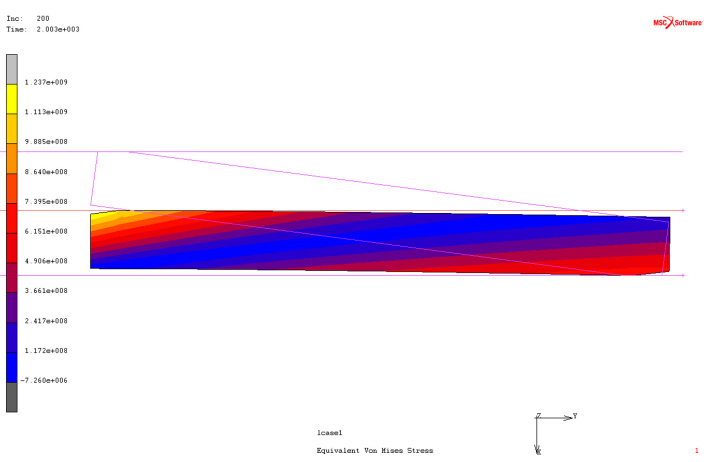

(a) Single disk

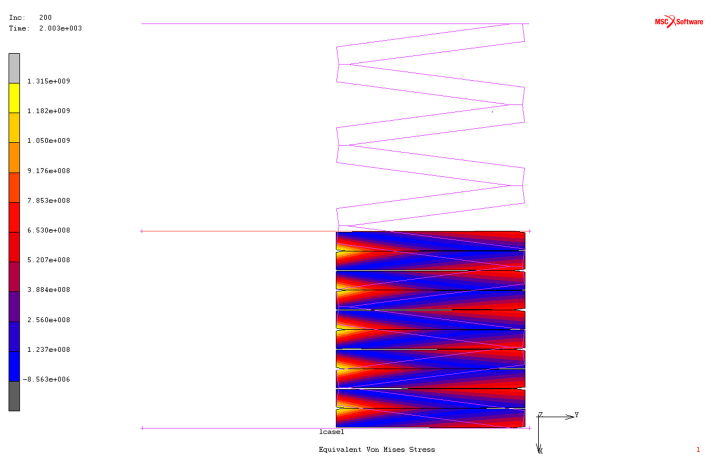

(b) Series stack of 10 disks

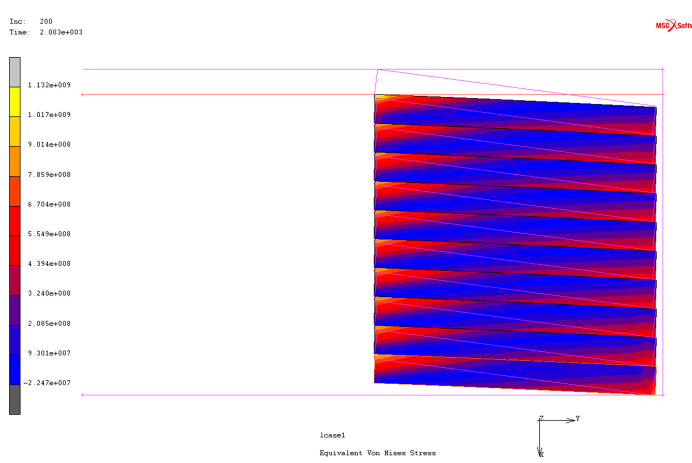

(b) Parallel stack of 10 disks

Fig. 9 Von mises stress distributions of disk springs with friction coefficient 0.01

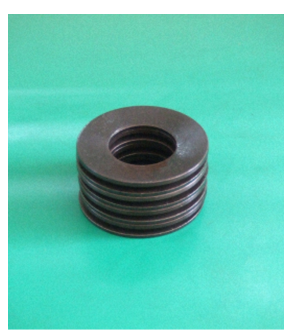

(a) Series stack

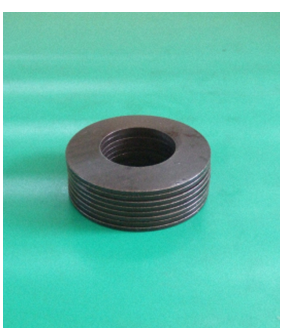

(b) Parallel stack
Photo. 1 Disc springs 


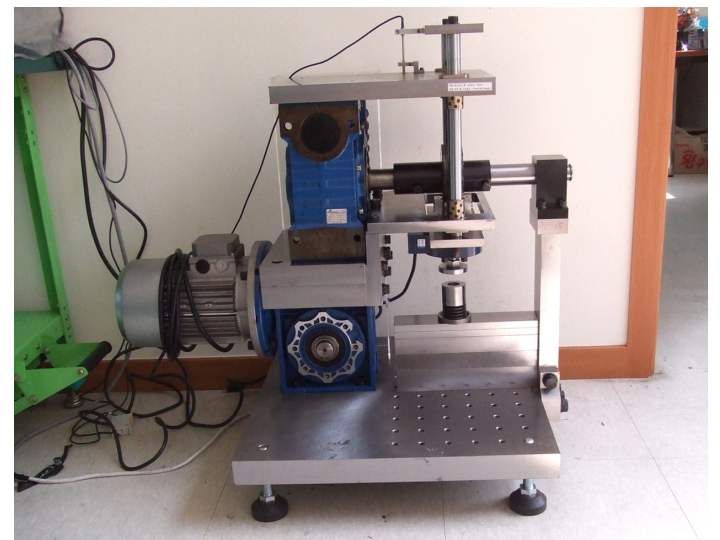

Photo. 2 Experiment device

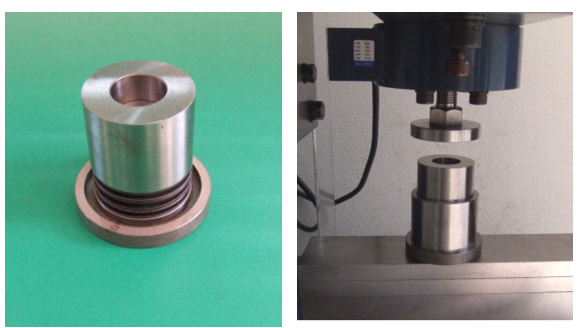

Photo. 3 Disc spring test fixture

\section{2 실험 결과}

Fig. 10은 직렬 적층된 접시스프링에 실험 장치를 통하여 하중을 가했을 때의 결과를 나타낸 것이다. 접시스프링은 2 개에서 10 개까지 2 개 단위로 적층하 여 실험하였다.

실험 결과는 동일 수준의 힘에 대하여 스프링의 개수에 증가에 따라 변위가 늘어남으로써 Fig. 7(a)

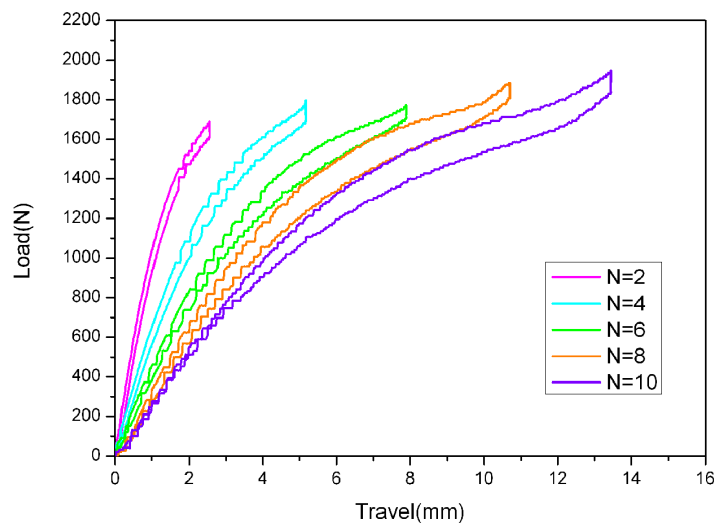

Fig. 10 Test results of serial stacks of disk springs

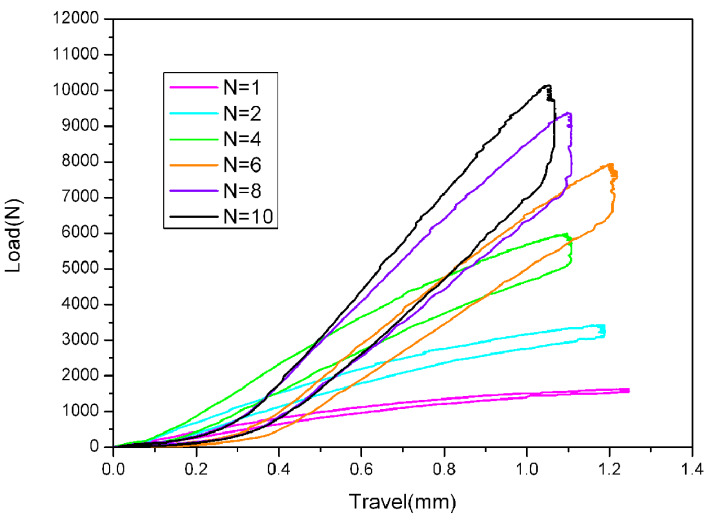

Fig. 11 Test results of parallel stacks of disk springs

의 수치해석 결과와 비교하여 볼 때 동일한 경향을 나타내고 있다. 그러나 수치해석 결과 그래프의 형 상과는 다소 다르게 직선에서 벗어나 있고 개수가 많아질수록 마찰력의 영향에 의한 이력현상이 두드 러지게 나타남을 알 수 있다.

Fig. 11은 병렬 적층된 접시스프링에 실험 장치를 통하여 하중을 가했을 때의 결과를 나타낸 것이다. 접시스프링은 최대 10 개까지 2 개 단위로 적층하여 실험하였다.

실험 결과는 Fig. 7(b)의 수치해석 결과와 비교하 여 볼 때 스프링의 개수가 늘어날수록 이력현상이 많이 나타는 점에서 동일한 경향을 나타내고 있다. 그러나 접시스프링의 개수가 6 개 이상에서는 이력 현상이 수치해석 결과보다 더 급격하게 증가하는 양상을 보이며, 증가 경향도 다소 차이를 나타낸다.

이것은 주로 해석에서 사용된 마찰모델과 실제 적층된 스프링 사이에서 작용하는 실제 마찰력의 차이에서 기인한 것으로 판단된다.

\section{4. 결 론}

본 연구에서는 직렬 및 병렬 적층된 접시스프링 에 대하여 수치해석과 실험을 수행함으로써 다음과 같은 결론을 얻었다.

1) 직렬 적층된 접시스프링에서는 스프링 개수의 증가에 따라 동일 수준의 힘에 대하여 변위가 비 례하는 경향을 가지며, 수치해석 결과에 비하여 실험 결과에서 더 많은 이력현상이 나타난다.

2) 병렬 적층된 접시스프링에서는 스프링 개수의 
증가에 따라 이력현상이 급격히 증가하며, 실험 결과에서는 일정 개수 이상의 스프링에서 이력 현상의 증가 경향이 둔화된다.

3) 수치해석 결과 접시스프링의 적층 개수가 많을 수록 스프링 내경에서 높은 응력이 발생하는데, 특히 직렬 적층의 경우 병렬 적층에 비하여 높은 응력이 발생한다.

따라서 다수의 스프링을 적층하여 시스템에 적용 하는 경우 원하는 특성을 얻기 위해서는 마찰에 의 한 이력현상을 고려하는 것이 중요하며, 특히 이력 현상이 두드러진 병렬 적층의 경우 적층에 따른 비 선형 특성을 충분히 나타내기 위한 해석 모델의 개 발이 필요하다고 판단된다.

\section{References}

1) R. L. Norton, Machine Design, An Integrated Approach, 4th Edn., Prentice Hall, USA, p.838, 2011.

2) J. O. Almen and A. Laszlo, "The Uniform Section Disk Spring," Transactions of ASME, Vol.58, No.4, pp.305-314, 1936.

3) MUBEA Korea Co., Ltd, MUBEA Disc Spring Manual, 2006.

4) A. Hagerodt, F. Kuchukay, D. H. Park, A. Heim and A. Rinsdorf, "Optimum Design of Return and Cushion Springs for Automatic Transmission Clutches," SAE 2001-01-0870, 2001.
5) S. G. Park, O. C. Kwon, N. Fawazi, J. E. Oh and J. Y. Lee, "Non-linearity Analysis of the Disc Spring According to Lamination Method Using Numerical Simulaton," Spring Conference Proceedings of KSPE, pp.189-190, 2008.

6) S. W. Bang, H. J. Lee, H. J. Sim, S. G. Park, J. Y. Lee and J. E. Oh, "Non-linearity Characteristics Consideration of the Disc Spring under Shock Using Numerical Analysis," Transactions of the KSNVE, Vol.18, No.2, pp.153-159, 2008.

7) D. H. Shin, J. E. Oh and J. Y. Lee, "Predictions of Load-displacement of the Disc Spring with the Friction," Spring Conference Proceedings of KSNVE, pp.572-577, 2011.

8) S. H. Ko and M. J. Choi, "On the Damping of a Shock Absorption Device Composed of Disk Spring Stacks," Journal of the KIGAS, Vol.12, No.4, pp.46-51, 2008.

9) Y. H. Kang, J. H. Hong, I. S. Joo, Y. S. Kim, T. J. Kim and S. K. Kang, "A Study on the Optimal Design Technique for Improving Fatigue Life of Return Spring," KSAE Spring Conference Proceedings, pp.642-647, 2002.

10) J. Y. Kim, J. G. Kim and H. J. Yoon, "Axial Stiffness Analysis of a Clutch Diaphragm Spring in Passenger Cars," Journal of the KSPSE, Vol.14, No.6, pp.35-40, 2010. 